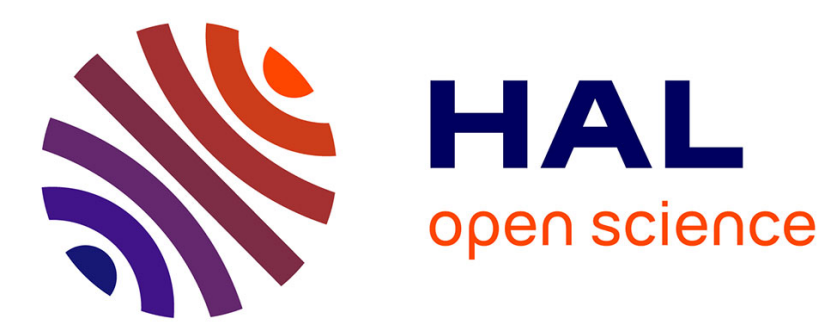

\title{
SINGLE PHOTON FREE-FREE TRANSITIONS
}

K. Bell

\section{To cite this version:}

K. Bell. SINGLE PHOTON FREE-FREE TRANSITIONS. Journal de Physique IV Proceedings, 1991, 01 (C1), pp.C1-49-C1-51. 10.1051/jp4:1991105 . jpa-00249743

\section{HAL Id: jpa-00249743 https://hal.science/jpa-00249743}

Submitted on 1 Jan 1991

HAL is a multi-disciplinary open access archive for the deposit and dissemination of scientific research documents, whether they are published or not. The documents may come from teaching and research institutions in France or abroad, or from public or private research centers.
L'archive ouverte pluridisciplinaire HAL, est destinée au dépôt et à la diffusion de documents scientifiques de niveau recherche, publiés ou non, émanant des établissements d'enseignement et de recherche français ou étrangers, des laboratoires publics ou privés. 


\section{SINGLE PHOTON FREE-EREE TRANSITIONS}

\section{K.L. BELL}

School of Mathematics and Physics, The Queen's University of Belfast, Belfast BT7 INN, Northern Ireland

Abstract - A brief review of single photon free-free transitions, in which a photon is absorbed by an electron in the presence of an atom, is presented.

\section{1 - INTRODUCTION}

An electron moving in the field of an atom A can absorb a photon of energy hv. These free-free radiative transitions are summarized by

$$
e_{i}+h v+A_{i} \rightarrow e_{f}+A_{f}
$$

where $i$ and $f$ denote the particles in their initial and final states, and where, in the final state, the particles may have different momenta and the atom may have a different internal state. Most of the theoretical and experimental work on these processes has however been restricted to the case in which the atom is both initially and finally in its ground state. In previous reviews /1/, /2/ all available theoretical and experimental data was considered for the absorption coefficient for the process in which the incident electron has low impact energies and for which the dipole approximation is valid in any theoretical treatment. Approximate methods of evaluating the absorption coefficient $K(\lambda, T)$ were also assessed ( $\lambda$ being the photon wavelength and $T$ the electron temperature). In general, recommended data was indicated in review /1/ for most atomic species whilst in review/2/ consideration was given to the atomic targets hydrogen, helium and argon. With the exception of these three atoms, atomic krypton and atomic carbon, the accuracy of the data for all other atoms remains unknown and further theoretical and experimental work is still required. The accuracy of the data for hydrogen, helium and argon is now considered to be sufficient for most applications.

In this article we up-date the reviews $/ 1 /, / 2 /$ by considering the only new data theoretical work for atomic carbon and krypton and experimental and theoretical work for atomic helium.

\section{$2-\underline{k}(\lambda, T)$ FOR ATOMIC KRYPTON}

Two calculations now exist for the absorption coefficient of the negative krypton ion in which wavefunctions are determined and used to evaluate the relevant matrix elements without any approximation. Geltman /3/ employed a a single-channel approximation using a model, atomic potential whilst Bell et al /4/ employed a two-state ${ }^{\mathrm{L}} \mathrm{S}$, ${ }_{\mathrm{P}}{ }^{\circ} \mathrm{R}$-matrix method (the ${ }^{1} \mathrm{p}^{\mathrm{O}}$ state being a pseudo-state to allow for the ground state static dipole polarisability). Both calculations are restricted to the case of the krypton atom remaining in its ground state in the free-free process. Table 1 compares their results at three electron temperatures for a range of photon wavelengths.

Table $1 \mathrm{Kr}^{-}$free-free absorption coefficient: ratio of results $/ 4 /$ to results $/ 3 /$.

$\begin{array}{cllr}\lambda(\mu \mathrm{m}) / \mathrm{T}(\mathrm{K}) & 2500 & 5000 & 10000 \\ 0.5 & 1.48 & 1.29 & 1.19 \\ 2.0 & 0.7 & 0.84 & 0.94 \\ 10.0 & 0.57 & 0.78 & 0.91 \\ 20.0 & 0.57 & 0.77 & 0.91\end{array}$

Geltman's /3/ data always lies above the results of Bell et al /4/ for long wavelengths and below for the short wavelengths. However with increasing temperature an improvement is seen in the agreement between the two calculations, at the highest temperature the 
difference being only $10-20 \%$. Since both calculations were performed in the length formulation, the differences are attributable to differences in the asymptotic wavefunctions. A measure of the accuracy can therefore be obtained from the scattering phaseshifts. Bell et a1 /4/ found their low-energy phaseshifts to be in exceptionally good agreement with experiment and this would suggest that their data for longer wavelengths and lower temperatures is preferable to that of Geltman /3/. Thus the data for all $\lambda$, $\mathrm{T}$ of Bell et al $/ 4 /$ is recommended - for high temperatures and $\lambda \geq 2(\mu \mathrm{m})$ it is probably accurate to better than $20 \%$.

\section{$3-\underline{\mathrm{K}(\lambda, \mathrm{T}) \text { FOR ATOMTC CARBON }}$}

Atomic carbon is one of the few elements for which consideration has been given to a change in the internal state of the atom. The absorption coefficient has been calculated for the processes

$$
\mathrm{e}+\mathrm{hv}+\mathrm{C}\left({ }^{3} \mathrm{P},{ }^{1} \mathrm{D},{ }^{1} \mathrm{~s}\right) \rightarrow \mathrm{e}+\mathrm{C}\left({ }^{3} \mathrm{P},{ }^{1} \mathrm{D},{ }^{1} \mathrm{~S}\right)
$$

by $B_{\text {ejll }}$ et al $/ 5 /$ and John and Williams /6/. Bell et al /5/ employed a six-state ${ }^{3} \mathrm{P}$, ${ }^{1} \mathrm{D}$, ${ }_{\mathrm{S},}{ }_{\mathrm{P}}{ }^{\circ},{ }^{3} \mathrm{D}^{\circ},{ }_{\mathrm{S}}{ }^{\circ}$ R-matrix approximation whilst John and Williams/6/ employed an asymptotic approximation for the evaluation of the required matrix elements utilising the results of a Bethe-Goldstone approximation for the e - C scattering process. Geltman /3/ employed a single-channel approximation using a model potential but only considered the case of the atom being initially and finally in its ground ${ }^{3} \mathrm{P}$ state. His results however may be seriously in error since the elastic scattering cross sections obtained by him failed to account for the low-energy ${ }_{\mathrm{P}}{ }^{\circ}$ shape resonance which dominates the low-energy scattering. Figure 1 compares the results of these three calculations for the absorption coefficient.

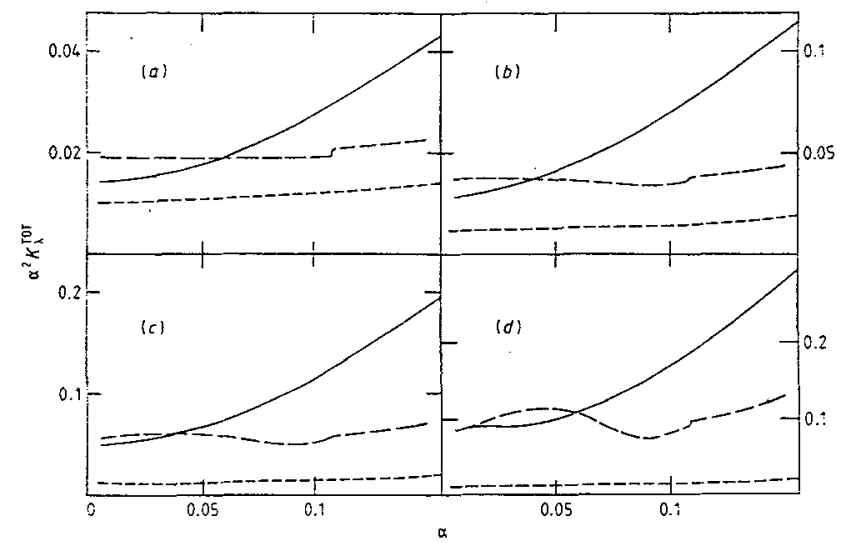

Fig. 1 - Scaled total absorption coefficient $\alpha^{2} \mathrm{~K}^{\text {TOT }}$ plotted against $\alpha$ where $\alpha=$ $911.27 \lambda^{-1}(\AA) ;-15 / ;--/ 6 / ;--13 \lambda . \quad$ (a) $\mathrm{T}=10080$; (b) $\mathrm{T}=5040$; (c) $\mathrm{T}=3150$; (d) $\mathrm{T}=1800$.

Geltman's data lie significantly lower than /5/, /6/ presumably because of the inability to account for the low-energy $\mathrm{P}^{\circ}$ shape resonance. The results /5/ and /6/ show significant disagreement, although for small values of the temperature $T$ and large wavelengths better accord is found. This lack of agreement makes it difficult to access the accuracy of the absorption coefficient for this atom. It can only be concluded that the data /5/ must represent the best available given that this calculation has been performed using sophisticated electron scattering wavefunctions and that the matrix elements have been evaluated without approximation. 
The data for the absorption coefficient of the negative helium ion has been reviewed in /2/. In this section we draw attention to recent novel experiments in simultaneous electron photon excitation (SEDE). The first observation of such a process was by Mason and Newell /7/ for the helium $1^{1} \mathrm{~S}-2^{3} \mathrm{~S}$ transition

$$
e+h v+\operatorname{He}\left(1^{1} s\right) \rightarrow e+\operatorname{He}\left(2^{3} s\right)
$$

using a low-power $\mathrm{CWCO}_{2}$ single-mode laser. In this process the excitation of the $2^{3} \mathrm{~S}$ state of helium is accomplished by the absorption of a quantum of radiation from the laser field combined with a simultaneous inelastic electron scattering in which the electron provides the energy decrement required to excite the $2^{3} \mathrm{~s}$ state. Such work has since been confirmed by Wallbank et af $/ 8 /$ using a pulsed $10 \mathrm{MWCO}_{2}$ laser and these authors have extended the SEPE process to the $1 \mathrm{I}_{3}{ }_{2} \mathrm{~S}$ transition /9/. Mason and Newell /10/ have presented improved data on the $1^{1} \mathrm{~S}-2^{3} \mathrm{~S}$ transition, and more recently /11/ have extended the work to use of circularly polarised radiation. For low energy incident electrons there is only one theoretical paper on the SEPE process. Geltman and Maquet /12/ have considered the $1^{1} \mathrm{~S}-$ $2 \mathrm{~S}$ transition by extending the well known soft photon approximation for elastic scattering in the presence of a laser to the inelastic scattering process employing the results of a 5-state R-matrix excitation calculation. They, however, only considered plane polarised radiation parallel to the incident electron beam direction. Nevertheless good agreement was found between theory and the appropriate experiments. Theoretical calculations are clearly required both of a more sophisticated nature and with consideration of both plane polarised and circularly polarised radiation.

\section{REFERENCES}

/1/ Be11, K. L. Daresbury Laboratory Report, DL/SCI/R24 (1986).

/2/ Bell, K. L. Atomic Data Workshop, St. Catherine's College Oxford (1987).

$/ 3 /$ Geltman, S. J. Quant. Spectros. Radiat. Transfer 13 (1973) 601.

$14 /$ Be11, K. L., Berrington, K. A. and Hibbert, A. J. Phys. B: At. Mol. Opt. Phys. 21 (1988) 4205.

/5/ Bel1, K. L., Hibbert, A. and Berrington, K. A. J. Phys B: At. Mo1. Opt. Phys. 21 (1988) 2319.

/6/ John, T. L. and Williams, R. J. Mon. Not. R. Astron. Soc. 181 (1977) 483.

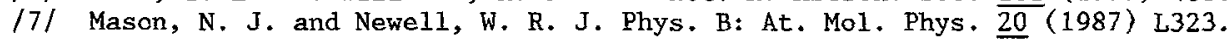

/8/ Wallbank, B., Holmes, J. K., Le Blanc L. and Weingartshofer, A. Z. Phys. D 10 (1988) 467.

/9/ Wallbank, B., Holmes, J. K. and Weingartshofer, A. J. Phys. B: At. Mo1. Opt. Phys. 22 (1989) L615.

/10/ Mason, N..J. and Newel1, W. R. J. Phys. B: At. Mol Opt. Phys. 22 (1989) 777.

/11/ Mason, N. J. and Newel1, W. R. J. Phys. B: At. Mo1. Opt. Phys. 23 (1990) L179.

/12/ Geltman, S. and Maquet, A. J. Phys. B: At. Mo1. Opt. Phys. 22 (1989) L419. 